\title{
The Role of Extracellular Space (Apoplast) in The Regulation of Physiological Processes in Plants
}

\author{
VI Chikov*, GA Akhtyamova and SN Batasheva \\ FRC Kazan Scientific Center of RAS, Russia
}

*Corresponding author: VI Chikov, FRC Kazan Scientific Center of RAS, Russia.

Received Date: August 09, 2018

Published Date: January 11, 2019

\begin{abstract}
The paper summarizes the results of studies of the role played by the plant leaf extracellular space in the regulation of mesophyll cells water exchange, photosynthesis and export of assimilates to consuming sink organs. When comparing different methods of assessing water exchange rates, the participation of the plasmalemma in the formation of the leaf water potential was shown. Using the in vivo method of extracting the contents of the apoplast, the dynamics of the exit and movement of labeled photosynthetic products through the extracellular space was traced. It was shown that there is a circulation of assimilates in the plant. As the sugars move downwards along the phloem, they partially escape into the extracellular space and are carried away upwards by the transpiration stream, where they re-enter the leaves that have completed growth and are re-exported. This creates a common pool of photosynthetic products, which serves as a test of the balance between photosynthesis and the use of assimilates by consuming organs. Analysis of the metabolism of ${ }^{14} \mathrm{C}$-labelled photosynthetic products in genetically transformed plants with increased or decreased apo plastic invertase activity showed the key importance of this enzyme in the regulation of photosynthesis and export of ${ }^{14} \mathrm{CO}_{2}$ assimilation products from the leaf. Simultaneous measurement of photosynthesis and transpiration in leaves of these plants under rapid changes in light exposure showed a regulatory link of photo processes in chloroplasts, dark reactions of carbon dioxide assimilation by mesophyll cells and transport of assimilates into phloem, the actuator of which is the leaf stomata. If the balance between photo-processes and the reduction of $\mathrm{CO}_{2}$ to sugars in the cell is disturbed, the ratio of sugars to organic acid changes, which leads to a pH shift in mesophyll cells, and then in the apoplast, which alters apo plastic invertase activity. Accordingly, depending on the degree of sucrose hydrolysis in the apoplast, the osmolarity of the extracellular medium changes $(1$ mole of sucrose $\rightarrow 2$ moles of hexoses), increasing with approaching to the stomatal aperture, which affects the stomata and leaf resistance to $\mathrm{CO}_{2}$ diffusion. As a result, the ratio between light and dark processes is normalized.
\end{abstract}

Keywords: Photosynthesis; Apoplast; Cell water exchange; Nitrates; Nitric oxide; Invertase; Transport of assimilates; Photo processes of chloroplasts

\section{Introduction}

Some 50 years ago, there was a firm belief that in plants the extracellular space contains mainly water and also minor quantities of minerals and low-molecular weight compounds involved in metabolism. An important obstacle in the development of this important area of plant physiology and biochemistry was the lack of methods and experimental approaches for the correct study of this space in vivo. However, already in the early works of A.L. Kursanov and his colleagues [1,2] it was shown that the transported compound of photosynthesis, sucrose, undergoes hydrolysis in the extracellular space of the leaf. From this it followed that active enzymes function in the extracellular space and are quite likely to participate in the regulation of the transport of photosynthetic products.
These data were obtained in experiments where either leaf cuts were used, or water was sucked under a slight pressure through a part of the leaf blade. Both methods were too inert and disrupted the in vivo state of the leaf.

Under the influence of these studies, a method [3] for studying the extracellular space using a pressure chamber, originally proposed by [4] for determining leaf water potential, was developed in the Laboratory of photosynthesis of the Kazan Institute of Biochemistry and Biophysics. This method allowed in vivo tracing of the dynamics of labeled photosynthetic product exit and movement through the extracellular space. Later, [5] also proposed the method of centrifuging leaves after infiltration with water 
or various solutions, which allowed extracting large quantities of substances from the extracellular space. All this allowed us to expand our understanding of the role played by the apoplast in the regulation of photosynthesis and assimilate transport, and even led to the conclusion that there exists an independent biochemistry of the apoplast [6].

\section{Osmotic gradient between leaf mesophyll cells and extracellular fluid}

The study of extracellular (free) space began with the study of water exchange of plant cells. Water holding capacity (WHC) of cells is one of the important parameters of plant water exchange. WHC is characterized by the amount of water remaining in the cell after the action of a certain dehydrating factor (low water vapor pressure, high osmotic pressure of the solution). It was assumed [7] that water removal from cells is determined only by the gradient of water activity inside and outside the cells (i.e. depends only on the state of intracellular water). Accordingly, WHC was evaluated by the direction of water movement (inward or outward) after placing a tissue (leaf cuts) in solutions of sucrose of different concentrations [8]. The index obtained by this method was expressed as the concentration of osmotic substances equivalent to the suction force of the intracellular solution. However, this method is rather laborious and, most importantly, does not exclude the possibility of movement of osmotically active substances through the plasma membrane of the cells being measured. For faster and more accurate determination of the leaf WHC directly in energy units (bar) we used a "pressure chamber" [4].

To measure the leaf water capacity using a pressure chamber (Figure 1, A), the experimental leaf was placed inside a firm chamber into which compressed nitrogen was injected from a balloon through a reducer. By gradually increasing the external pressure of nitrogen on the leaf inside the chamber to the point where this external pressure exceeds the water potential of the leaf, it is possible to achieve the situation when water from the mesophyll cells starts to move in the opposite direction (from cells to the conductive system and outwards through the leaf petiole). This moment is easily recorded by an accurate manometer at the moment the water film appears on the fresh cut of the petiole. The entire measurement process takes 1-1.5 minutes. The principle of operation of the pressure chamber is easier to understand on the following model (Figure 1, B). Imagine that we have two vessels communicating with each other through a durable semipermeable membrane $(\mathrm{m})$, which only transmits water molecules. We pour clean water into one of the vessels, for example, a left one. It will penetrate into the adjacent vessel and settle at a certain level (a).
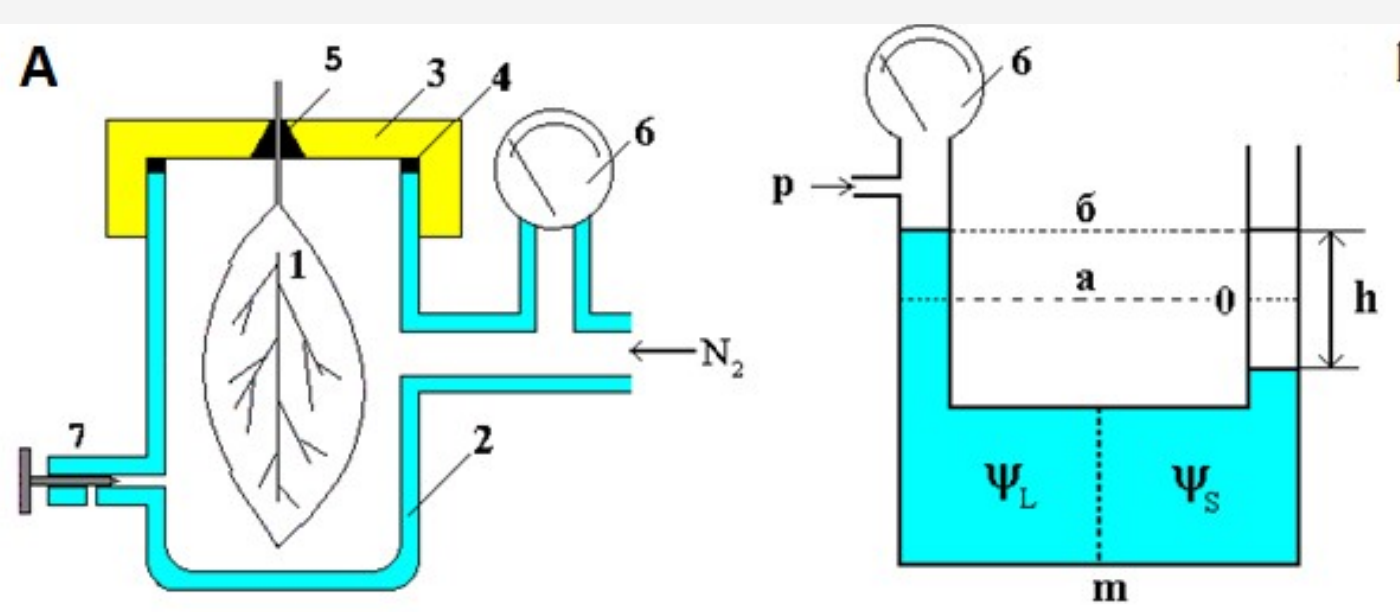

B

Figure 1: Scheme representing the action of a pressure chamber during measurements of water potentials of plant leaves [3]. A - pressure chamber

B - the model explaining the principle of pressure chamber action; 1 - leaf; 2 - pressure chamber body; 3 - screw cap; 4 - rubber seal; 5 - airproof plug; 6 - pressure gauge; 7 - discharge cock; $\mathrm{m}$ - semi-permeable membrane. See the text for explanations.

If now an osmotic is dissolved in the first vessel, then we get a solution with a certain osmotic potential $\Psi$ L. Under the laws of osmosis water from the right vessel will begin to move to the left vessel. As a result, the level of the liquid in the right vessel will begin to drop, and in the left, it will rise. This will continue until the additional pressure of the liquid column in the left vessel, resulting from the level difference $(\mathrm{h})$, compensates for the osmotic pressure of the solute. If, after equilibrium is established, an additional pressure $\mathrm{P}$ is applied to the surface of the liquid in the left vessel to return the liquid levels in both vessels to the initial state (a), then the value of this pressure will correspond to the osmotic potential $\Psi_{1}$ of the solution and can be measured by a manometer (6).
A similar situation occurs when we measure the leaf water potential by a pressure chamber. Only instead of the left vessel on the model there is the integral water potential of all leaf cells, and as the right vessel is xylem fluid. The moment when xylem fluid appears outside the pressure chamber at the cut of the leaf petiole will correspond to the liquid level (a) in the model (B). By analogy with the model at this point, the fluid level will be returned to the initial state and the following equality will hold true:

$$
\mathrm{P}=\Psi \text { leaf }-\Psi \text { xylem sap }
$$

where $P$ is the gas pressure in the chamber, $\Psi_{\text {leaf }}$ is the leaf water potential, $\Psi_{\text {xylem }}$ is the water potential of the extracellular fluid. 
Since according to a number of researchers the value of the water potential of plant xylem sap is practically equal to the potential of pure water (for most plants under normal conditions it is in the range of 0.1-0.3 atm, and the leaf water potential is usually several atmospheres), then the former can be neglected and $\mathrm{p}=$ $\Psi$

However, if the osmotic potential of the xylem sap $\Psi_{x y l e m}$ is far from zero, then values of $\Psi_{\text {leaf }}$ will be overestimated by an amount of $\Psi_{\text {xylem }}$ when measuring the water potentials of the leaves. In the model (in Figure 1, B), this overestimation will be observed if the semipermeable membrane loses its selectivity and transmits some osmotically active substances from the left to the right vessel.

As noted above, the osmotic method of N.A. Gusev can give erroneous results in the case of disturbed permeability of the plasma membrane of mesophyll cells. This means that these methods should give significant differences in results in those cases when the plasma membrane permeability of mesophyll cells changes. Indeed, a comparison of these two methods showed their essential difference [9]. For example, in plants sprayed with the emulsion of the organophosphorus insecticide Rogor $\left(5^{*} 10^{-2} \mathrm{M}\right)$, $\Psi_{\text {leaf }}$ values measured with a pressure chamber were twice the control (-2.61 atm) and (-4.91 atm), respectively, and the suction power of cells, measured with the Gusev's method, was also above the control (5.37 \pm 0.41 and $3.44 \pm 0.40$ atm, respectively). At the same time, the water content of the leaves of treated plants was significantly lower than that in control $(6.98 \pm 0.18 \mathrm{~g} / \mathrm{g}$ versus 7.77 $\pm 0.16 \mathrm{~g} / \mathrm{g})$.

The data cited indicate that using a pressure chamber, the researcher receives information only about the gradient between water potentials of the leaf mesophyll cells and the extracellular aqueous medium. In the treated plants, water deficiency of the cell interiors is greater than in the control. This was evidenced by a more than two times lower transpiration of the treated leaves [10] (635 $\pm 47 \mathrm{mg} \mathrm{H}_{2} \mathrm{O} / \mathrm{g}$ of fresh weight in control and $276 \pm 24$ in the plants treated with Roger).

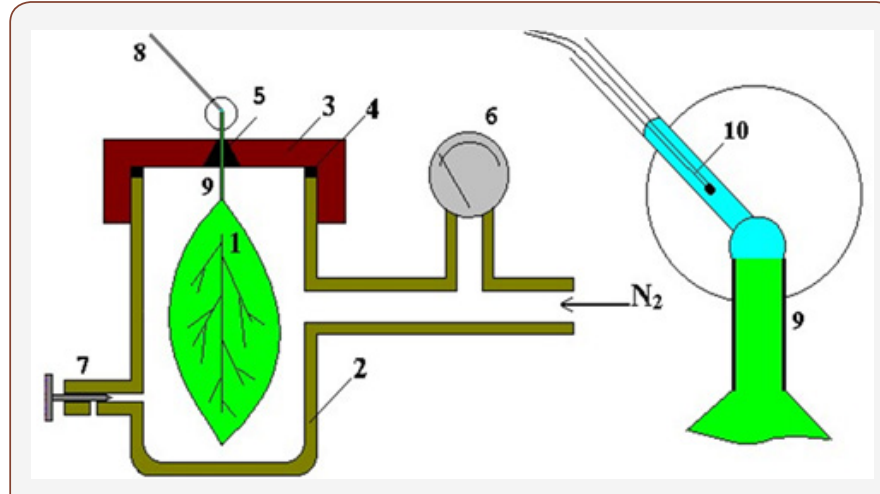

Figure 2: The scheme of collecting xylem sap and measuring its osmolality.

(1 - 7 as in Figure 1) leaf; 8 - capillary with a thermocouple for collecting the fluid evolved; 9 - the petiole of a leaf being measured; 10 - a thermocouple inside a capillary.

It was logical to assume that all these differences are associated with a decrease in the permeability of membranes of mesophyll cells for osmotically active substances. The release of these substances into the leaf apoplast reduced an osmotic gradient on the plasma membrane, which was registered by a pressure chamber during measurement of $\Psi_{\text {leaf }}$ To confirm the hypothesis that osmotic substances could be released into the apoplast, the water potential of xylem sap collected in a capillary was measured (as shown in Figure 2). The osmolarity of the extracellular fluid was measured by the freezing point using a micro-cryoscope, similar to that described in [11].

An experiment has shown that under the action of membraneactive substance aminazine $\left(10^{-3} \mathrm{M}\right)$ the osmotic potential of xylem sap has increased more than 30 times (from 0.06 to $1.99 \bullet 10^{5} \mathrm{~Pa}$ ), although the amount of water leaving the mesophyll cells increased only 2.5-3 times.

Determination of the cation composition $\left(\mathrm{K}^{+}\right.$and $\left.\mathrm{Na}^{+}\right)$of xylem sap in the treated and control plants showed that under the action of Roger, their concentration increased 1.4-1.9 times (Table 1).

Table 1: Effect of spraying cotton leaves with insecticide Roger $(0.1 \%)$ on the cation composition $\left(10^{-4} \mathrm{mg} / \mathrm{ml}\right)$ of extracellular fluid squeezed through the leaf petiole by a pressure 1-2 atm higher than leaf water potential.

\begin{tabular}{|c|c|c|c|c|c|}
\hline Treatment & Osmotic Potential (atm) & $\mathbf{K}^{+}$ & $\mathbf{N a}^{+}$ & $\mathbf{C a}^{2+}$ & $\mathbf{M g}^{2+}$ \\
\hline Control & $-0.06 \pm 0.02$ & $29.0 \pm 2.1$ & $1.7 \pm 0.3$ & $15.0 \pm 0.7$ & $24.0 \pm 1.0$ \\
\hline Insecticide Roger & $1.99 \pm 0.05$ & $57.0 \pm 1.9$ & $2.4 \pm 0.1$ & $13.2 \pm 0.7$ & $55.0 \pm 1.0$ \\
\hline
\end{tabular}

However, this could not explain the increase in osmolality of xylem sap by 30 times and indicated the important regulatory function of the apoplast not only in the control of leaf water exchange, but also of metabolism. All this moved us to a decision to use a pressure chamber to study the release of photosynthetic products into the apoplast.

\section{Composition of extracellular fluid}

An important aspect in the study of regulation of assimilates movement through the apoplast is elucidation of the complete composition and enzymatic activity of the medium into which the assimilates are released from mesophyll cells before being loaded into phloem. In the first experiments for studying the contents of the free space, water was sucked through the leaf $[12,13]$ or leaf cuts were washed with water $[1,11]$. The solution extracted from the apoplast consisted mainly of sugars, the concentration of which correlated with the export of assimilates from the leaf.

The concentration of sucrose and amino acids found in the apoplast was much lower than that in mesophyll cells or phloem sap [14]. This confirmed the conclusion that the transportation of sucrose to phloem occurs against the gradient of its concentration $[2,13]$. The percentage of individual amino acids (unlabeled) was 
similar in the cytosol, apoplast and phloem. The ratio of sucrose to amino acids in the cytosol was close to that in the apoplast, and it was 5 times higher in phloem. Low concentration of substances in the apoplast (measurements in xylem sap), apparently, was due to their strong dilution with transpiration water.

The release of photosynthetic sucrose in the mesophyll apoplast is likely to be involved also in the mechanism of regulation of the intensity of transpiration and photosynthesis by stomata, since a correlation was found between transpiration and sucrose content in the apoplast of the stomatal guard cells [15] (epidermis). Sucrose diffuses through the apo plastic fluid from the mesophyll cells to the stomata. This is evidenced by the dynamics of changes in the content of labeled sucrose in the cells of the palisade tissue and the stomatal guard cells [16].

$75 \%$ of the osmotic potential of the apo plastic content is determined by sugars and inorganic ions (mainly potassium, sodium and chloride). Divalent ions $\left(\mathrm{Ca}^{2+}\right.$ and $\mathrm{Mg}^{2+}$ ) have both free and exchangeable fractions in the apoplast, but this was not observed for potassium [17]. According to [18], the concentration of calcium and potassium in the apoplast varies from 0.3 to 0.8 and from 1.3 to $4.5 \mathrm{mM}$, respectively.

Almost half $(40 \%)$ of the calcium content in the leaf is in the apoplastic fluid, while for potassium and magnesium this value is only $1.8 \%$.

Measurement of the concentration of inorganic phosphate (Pi) in the apoplast [19] made it possible to establish the integrating role of the apoplast in plant phosphorus metabolism. Under phosphorus deficiency, it is transported through the apoplast from old leaves to young ones. The concentration of Pi in apoplast was maintained at a level of 0.1-1.0 mM even in the absence of phosphorus in the nutrient medium and was much higher than its usual concentration in soil solution (less than $1 \mu \mathrm{M}$ ).

The release of assimilates into the leaf apoplast. The study of the possibilities of existing methods for extracting substances from the apoplast and, in particular, the most advanced method of M.I. Brovchenko [13] showed that the pressure chamber can have important advantages: high productivity, complete extraction of photosynthetic products from the apoplast and their high concentration in the resulting solution, allowing chromatographic analysis of labeled compounds.

The first attempts to extract labeled assimilates from the apoplast of a native leaf gave very low results $10.25 \%$ of the mesophyll radioactivity), and to increase the completeness of the extraction of the apoplast contents, it was necessary to apply a too high pressure to the leaf in the chamber. This could provoke an excessive release of substances not occurring normally in vivo. Therefore, in the end, the following methodology was adopted. After a short (15-30 s) exposure of a native experimental leaf to ${ }^{14} \mathrm{CO}_{2}$ in the light, the leaf was cut and quickly infiltrated with water under vacuum conditions. Then, using a pressure chamber, the extracellular water was extracted through the petiole and collected by a piece of filter paper. In control experiments it was shown that if the pressure applied to the leaf in the chamber was equal to the corresponding value of leaf water potential (or greater by $1 \mathrm{~atm}$ ), which was previously estimated on similar leaves, then after 1520 min all water from the intercellular spaces was removed, and the water potential was restored to its original level. The latter was easily controlled by the disappearance of wet spots on the underside of the leaf.

After the extraction of the apo plastic content, the leaf and the collected fluid were fixed with boiling $70 \%$ ethanol. The volumes of fixed samples were assessed, and their radio activities were measured. If necessary, the water-alcohol-soluble compounds of the obtained samples were analyzed by paper chromatography and radioautography on X-ray films.

Kinetics of assimilates release into the apoplast. First of all, we were interested in how quickly the labeled photosynthetic compounds appear outside the plasma membrane and how their proportion (in \%) of the total leaf assimilate pool created in the process of photosynthesis in ${ }^{14} \mathrm{CO}_{2}$ is changing with time. An important characteristic of the kinetics of assimilate exit into the apoplast is a fairly rapid increase of the proportion of labeled compounds in this compartment followed by a decrease of this index to a stationary level (Figure 3).

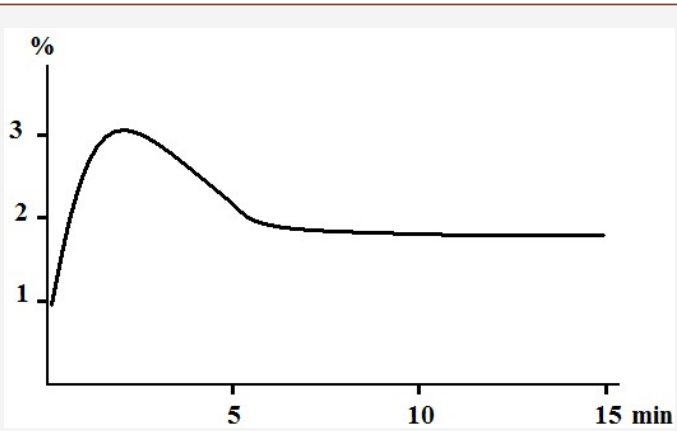

Figure 3: Kinetics of the ${ }^{14} \mathrm{C}$-assimilates release into the apoplast of a bean leaf (\% of the leaf radioactivity). The plants were 3.5 weeks old and grown under artificial illumination (10 klx).

Already after 30 seconds of leaf photosynthesis in ${ }^{14} \mathrm{CO}_{2}$ a significant fraction $(\approx 1.0 \%)$ of labeled assimilates is found in the apoplast. During the next two minutes, the fraction of ${ }^{14} \mathrm{C}$ in the apoplast grows (to $>3 \%$ ), which probably indicates the continuing assimilate release from mesophyll cells and filling of the apo plastic space. To $5 \mathrm{~min}$ the relative content of ${ }^{14} \mathrm{C}$ in the apoplast decreases, and then remains at a certain constant level (about 2\%) for a fairly long time. Since the volume of the apoplast, measured with dyes [20], is about $6-8 \%$ of the leaf water, the concentration of photosynthetic products in the apoplast is lower than that in the cells, but close to the average one throughout the mesophyll.

Thus, as soon as assimilation of ${ }^{14} \mathrm{CO}_{2}$ begins, the labeled products of photosynthesis leave the mesophyll cells, providing transportation of metabolites. The same kinetics is characteristic for label passage either through an intermediate compound to subsequent metabolites or through an intermediate compartment 
(the chain "assimilating cell $\rightarrow$ apoplast $\rightarrow$ phloem terminals"). If this is the case, then the conditions under which photosynthesis is carried out should influence this index. In connection with this, the task was to determine how the size of the assimilate pool in the apoplast depends on the conditions of plant growing, illumination, $\mathrm{CO}_{2}$ concentration and other factors.

\section{Influence of conditions on the content of assimilates in the apoplast}

The influence of drought. As experiments have shown, the conditions under which photosynthesis is occurring have a significant effect on the relative content of labeled carbon in the apoplast. Drought, for example, increases the accumulation of assimilates in the apoplast (Figure 4). It follows that the known phenomenon of inhibition of the outflow of assimilates from leaves during drought [21] is due to the difficulty of sucrose moving from the apoplast to phloem, and not to the formation of sucrose itself in the process of photosynthesis. This is most likely the reason of the nonspecific changes in the photosynthetic carbon metabolism (a decrease in the radioactivity of sucrose and a decrease in the ratio of sucrose to hexoses) observed by the author, since the sucrose accumulated in the apoplast is hydrolyzed by invertase (due to the increased concentration of the substrate).

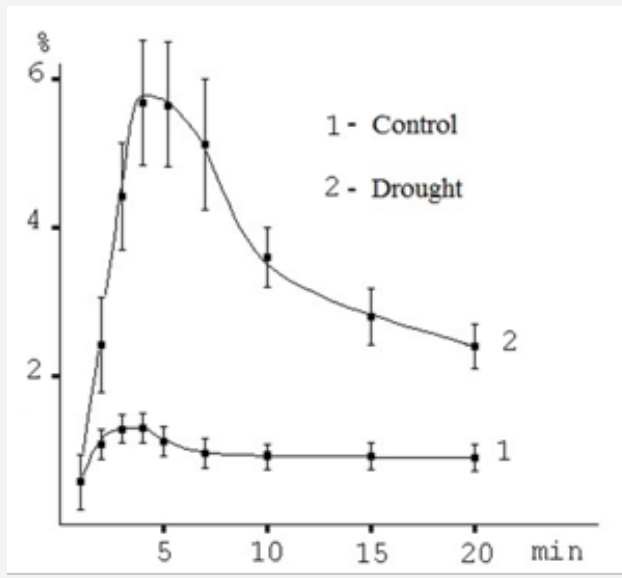

Figure 4: The influence of soil drought on the kinetics of $14 \mathrm{C}$-assimilates content in the apoplast after $15 \mathrm{~s}$ exposure of a bean leaf to ${ }^{14} \mathrm{CO}_{2}$ in the light [36].

The influence of $\mathrm{CO}_{2}$ concentration and illumination. A sudden increase in the amount of photo assimilates formed (as a result of an increase in the illumination or the concentration of $\mathrm{CO}_{2}$ ) causes an increased accumulation of sucrose in the apoplast (Figure 5). Although the exposure time of the leaf to ${ }^{14} \mathrm{CO}_{2}$ was short, an increase in the concentration of $\mathrm{CO}_{2}$ by a factor of ten significantly increased the mass of assimilates in the apoplast. These data once again show that photosynthesis is limited by the export function of the leaf. It is possible that the effect of an increased $\mathrm{CO}_{2}$ concentration is realized through a change in the $\mathrm{pH}$ of the apoplast, as it was shown that high concentrations of $\mathrm{CO}_{2}$ (more than 1\%) immediately acidified the apoplast [22]. But as follows from [23], changes in the $\mathrm{CO}_{2}$ concentration in the range of physiological values (as in our experiment) did not shift the apoplastic $\mathrm{pH}$.
Another way to increase the photosynthetic flow is to increase illumination. In one of the experiments, plants were grown under laboratory conditions with an illumination of $10 \mathrm{klx}$. The illumination of the attached experimental leaf at the time of ${ }^{14} \mathrm{CO}_{2}$ fixation was increased to $80 \mathrm{klx}$. It remained elevated for another 10 minutes of post-photosynthesis. The increase in illumination also led to an increase in the proportion of labeled assimilates in the apoplast (Figure 5). This means that the export of assimilates in low light is mostly hampered at the stage of sucrose loading into phloem terminals or its advancement in the phloem, but the release of sugars from mesophyll cells into the apoplast appears to be successful. A sudden increase in illumination increases the mass of the photosynthetic products formed, which leads to an even greater accumulation of assimilates in the apoplast.

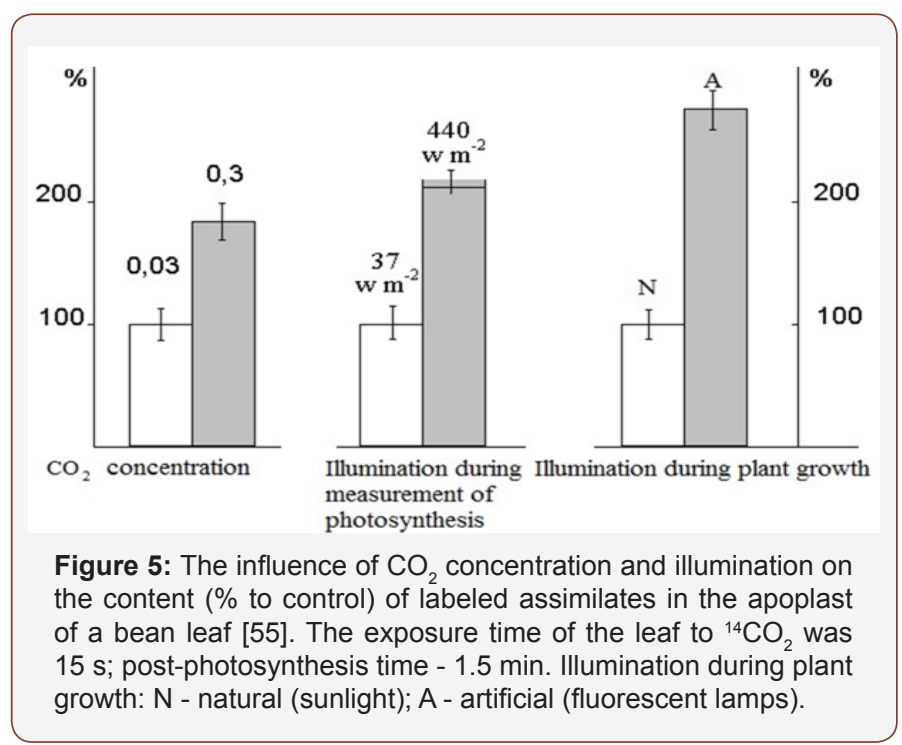

Conversely, if plants were grown at high illumination, the adjusted processes of photosynthesis, assimilate transport, and growth of sink organs in plants under bright light (natural sunlight) conditions contribute to a relative decrease in the proportion of assimilates in the apoplast. This is mainly due to the more successful filling (in conditions of high photosynthesis intensity) of mesophyll cells, and most importantly, the leaf conducting system (phloem vessels) with assimilates, at the background of which the radioactivity of the labeled products of photosynthesis in the apoplast decreases.

Since in plants grown at low illumination assimilation of ${ }^{14} \mathrm{CO}_{2}$ and the ${ }^{14} \mathrm{C}$ content in the apoplast increase with a sudden increase in light intensity, this allowed us to conclude [24] that weak photosynthesis in plants under shading conditions is limited by the assimilate loading into the phloem rather than by their formation in chloroplasts. It follows that to accelerate photosynthesis and plant productivity in low light conditions, it is necessary to look for ways to intensify the long-distance transport of assimilates.

Since in low light a decrease in the ratio of photosynthetically labeled sucrose to hexoses occurs in the leaf [25], then obviously under these conditions either a decrease in the intensity of sucrose synthesis occurs or already formed sucrose is more actively 
hydrolyzed producing hexoses. This once again confirmed that the leaf extracellular space represents an important component of the regulation of long-distance assimilate transport in the plant.

The $\mathrm{pH}$ of extracellular fluid. The apoplast contains enzymes, the activity of which depends on the $\mathrm{pH}$ of the medium. Therefore, it is very important to know $\mathrm{pH}$ parameters in the intercellular fluid. However, in the literature, information on this issue is rather contradictory. Some authors note a certain stability of the intercellular fluid $\mathrm{pH}$, while others show a difference in $\mathrm{pH}$ depending on the conditions or composition of the tissues.

Apparently, this is due to the difference in methods used for this purpose. If $\mathrm{pH}$ was determined [5] in the fluid recovered from tissues by centrifugation, then the integral data were obtained, which changed little and were close to $\mathrm{pH}$ value of 6.1. If authors used non-destructive methods in which leaves were perfused with fluorescent dyes $[18,26,27]$, and it was possible to visually determine the local $\mathrm{pH}$ changes, then significant differences in this index were found. This suggests that a local pH disturbance is most likely supported by some dynamic processes (occurrence or use of $\mathrm{H}^{+}$) in the apoplast.

In the xylem, the pH was 0.3-0.5 units lower than that in the apoplast of phloem companion cells [27]. In the same experiments, it was shown that apoplastic $\mathrm{pH}$ around stomata is $0.5-1.0$ units higher than that of epidermal cells. The presence of such $\mathrm{pH}$ gradients, in the absence of any barriers in the leaf apoplast, suggests the possibility of appearance of local changes in $\mathrm{pH}$ value. It should be noted that measurements using fluorescent dyes were carried out [26] on cut leaves and cutting itself undoubtedly changes the transport processes of substances and all the gradients. Since these processes are dynamic, it is likely that $\mathrm{pH}$ measurement data may also be somewhat distorted in comparison with the situation in a native plant.

In addition, tissues of a cut plant in which a fluorescent dye is introduced can also change their functional state. Moreover, after infiltration of the dye, it is required to remove its excess by centrifugation for 5 minutes at $450 \mathrm{~g}[28,29]$. Such effects undoubtedly significantly change the course of physiological processes in vivo, as evidenced by measurement of the respiration rate of experimental tissues, which is an order of magnitude lower than that observed in native plants [29].

Under these conditions, the effects of $\mathrm{pH}$ or respiration changes registered by the authors may be just a reaction of the plant normalizing the state of its cells. It should also be noted that in such experiments the fundamental rule of any experiment is violated: the oneness of the difference, according to which the compared objects must differ only by one feature. Therefore, the interpretation of the results of experiments, where a number of effectors acts simultaneously, must be done cautiously.

The use of fluorescent methods for measuring $\mathrm{pH}$ in the apoplast is of great importance, since it allows one to assess the possibilities of regulating this index by leaf cells. So, in the work
[28] by using this approach a conclusion was made about the significant regulatory capabilities of protoplasm in maintaining $\mathrm{pH}$ in various cell compartments, including that in the apoplast. However, the data on the buffering capacity were obtained using such non-physiological effects as the concentration of $\mathrm{CO}_{2}$ more than $1 \%$. Under such conditions, undoubtedly, the activity of numerous (more than 30) decarboxylating enzymes is blocked.

The lack of similarity between the $\mathrm{pH}$ measurement data obtained by different researchers can also be related to the heterogeneity of this index in separate areas of the apoplast space, since it is established that the density of proton pumps on the surface of different leaf cells varies greatly. Using immune methods in combination with electron microscopy, it was shown [30] that $\mathrm{H}^{+}$-ATPases are more densely located on the surface of transfer cells and especially on the lateral surface of phloem sieve tubes. These data indicate that a different density of proton pumps on the cell surfaces can create local pH gradients that are likely to have a regulatory role in the transport of substances. Apoplastic $\mathrm{pH}$ in the leaf substomatal cavity can affect stomatal movements and, according to [23], is a regulatory factor in response to various stressors. It may probably act as a signal during drought and salt stress [31].

Hydrolysis of sucrose in the apoplast is carried out by invertase whose optimal activity lies in the acidic $\mathrm{pH}$ range [32]. Apparently, changes in $\mathrm{pH}$ of the extracellular fluid can affect the process of sucrose hydrolysis in the apoplast. This working hypothesis was tested in a special experiment. Bean plants grown in small plastic vessels were placed under a glass jar, as shown in Figure 6 together with a Petri dish containing either a solution of hydrochloric acid or ammonia. Water was used as control. $\mathrm{NH}_{3}$ dissolving in apoplastic water binds $\mathrm{H}^{+}$and causes rapid alkalization as a direct result of the formation of $\mathrm{NH}_{4}^{+}[20]$.

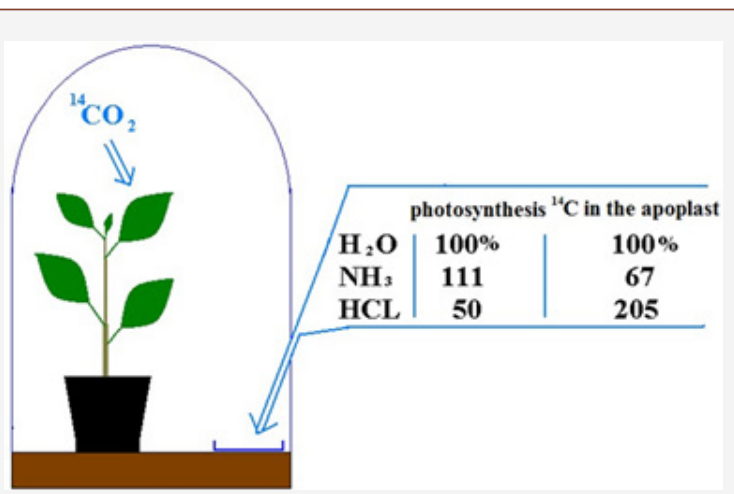

Figure 6: Effect of apoplast acidification or alkalization on photosynthesis and apo plastic $14 \mathrm{C}$ content in the leaves of bean plants [55].

As experiments showed, acidification of the medium inhibited photosynthesis and labeled assimilates accumulated in the apoplast. Alkalization led to the converse effects (Figure 6). The opposite effects of $\mathrm{HCl}$ and $\mathrm{NH} 3$ vapors on photosynthesis and ${ }^{14} \mathrm{C}$ content in the apoplast indicate that the key factor during sucrose loading into the phloem terminals is the $\mathrm{pH}$ of the apoplast medium which affects invertase activity. 
Stimulation of photosynthesis in the $\mathrm{NH}_{3}$ variant is impossible without the successful export of assimilates from the leaf. An excess of assimilates had to accumulate in the apoplast; however, this did not happen. Hence, assimilates successfully overpassed this intermediate compartment. Accordingly, with a deficiency of assimilates due to two-fold inhibited photosynthesis under $\mathrm{HCl}$ action, their accumulation in the apoplast is difficult to explain without recognizing a decrease in the sucrose evacuation from the leaf along the phloem.

Table 2: The influence of $\mathrm{HCl}$ concentration (\%) in gasholder on ${ }^{14} \mathrm{C}$ incorporation into some soluble products of 3-minute photosynthesis in cotton leaves (\% of radioactivity of alcohol water-soluble fraction).

\begin{tabular}{|c|c|c|}
\hline \multirow{2}{*}{ Labeled Substances } & \multicolumn{2}{|c|}{ HCl Concentration (\%) } \\
\cline { 2 - 3 } & $0.3-0.5$ & $2.0-2.5$ \\
\hline Phosphorous Esters of Sugars & 19.1 & 4.4 \\
\hline Sucrose & 48.7 & 10.5 \\
\hline Hexoses & 0.9 & 50.9 \\
\hline Alanine & 6.8 & 8.3 \\
\hline Others & 24.5 & 25.9 \\
\hline
\end{tabular}

It is characteristic that the acidity of the extracellular medium radically changed the ratio of labeled products of photosynthesis. The excess concentration of $\mathrm{HCl}$ in the acidified gasholder solution used for the displacement of The excess concentration of $\mathrm{HCl}$ in the acidified gasholder solution used for the displacement of The excess concentration of $\mathrm{HCl}$ in the acidified gasholder solution used for the displacement of ${ }^{14} \mathrm{CO}_{2}$ from $\mathrm{NaH}^{14} \mathrm{CO}_{3}$ caused a decrease in the incorporation of ${ }^{14} \mathrm{C}$ into sucrose and an increase in the label incorporation into hexoses (Table 2) from $\mathrm{NaH}^{14} \mathrm{CO}_{3}$ caused a decrease in the incorporation of ${ }^{14} \mathrm{C}$ into sucrose and an increase in the label incorporation into hexoses (Table 2) from $\mathrm{NaH}^{14} \mathrm{CO}_{3}$ caused a decrease in the incorporation of ${ }^{14} \mathrm{C}$ into sucrose and an increase in the label incorporation into hexoses (Table 2). By the way, the decrease of the ${ }^{14} \mathrm{C}$ content in phosphorus esters of sugars (PES) at acidification of the gas environment around the leaf indicates that their metabolism to sucrose was not suppressed. The formation of other labeled compounds also changed a little. All this indicates that main changes in the incorporation of labeled carbon into sucrose and hexose occurred as a result of an acute stimulation of sucrose hydrolysis in the apoplast.

\section{Participation of the apoplast in the regulation of long- distance transport of assimilates in the plant}

The distribution of assimilates in the plant occurs in accordance with the needs of its individual tissues and organs in substances. In this connection, there is an assumption [1] that consuming organs direct the flow of assimilates by sending a kind of "request" to photosynthetic organs. That is why the main attention of researchers in the study of long-distance assimilate transport was given to processes at the start (source leaf) or finish (sink for assimilates) of this pathway, while a passive role was assigned to the intermediate link (stem). These ideas somewhat distracted the attention of researchers from intermediaries between the source and the sink of assimilates, which were never found. At the same time, AL Kursanov [1] noted the possible involvement of stem in the regulation of long-distance transport of assimilates.

These data were subsequently confirmed by studying the kinetics of transport of assimilates labeled with short-lived carbon isotope ${ }^{11} \mathrm{C}$ (Figure 7). The authors photosynthetically introduced the labeled ${ }^{11} \mathrm{CO}_{2}$ into a leaf in the middle of a bean plant, and then the kinetics of the label appearance in the stem above and below the donor leaf was determined. The experiments showed that in the ascending direction there were two time components - fast (tens of seconds) and slow (tens of minutes). In the descending direction, only the slow component was observed.

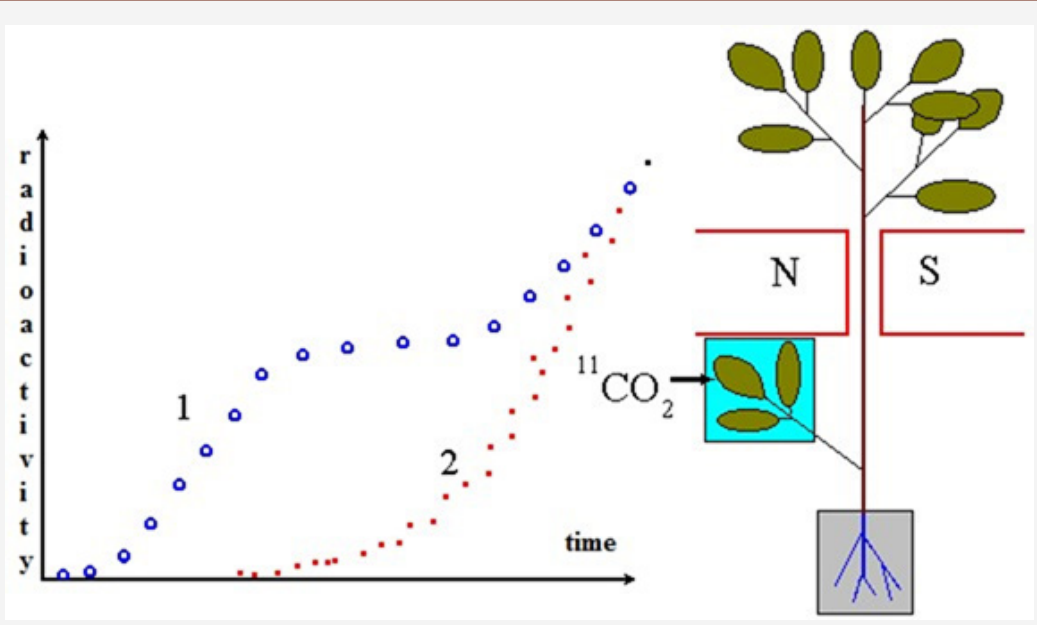

Figure 7: The dynamics of appearance of labeled ${ }^{11} \mathrm{C}$-assimilates above (1) and below (2) the 11Cdonor leaf [33].

From this the authors concluded that the labeled products of photosynthesis, when moving along the phloem of the stem, go into the apoplast, where they are carried away upwards by the transpiration water. Since the intensity of transpiration is 2-3 orders of magnitude higher than that of photosynthesis, the upward transfer has a high rate. In the descending direction, only the movement of labeled assimilates in the phloem is observed, the rate of which is much lower. According to AL Kursanov [1], it is 50$60 \mathrm{~cm} / \mathrm{h}$. 
The experiments of Minchin et al. were confirmed in our experiments with The excess concentration of $\mathrm{HCl}$ in the acidified gasholder solution used for the displacement of 14CO2 from $\mathrm{NaH}^{14} \mathrm{CO}_{3}$ caused a decrease in the incorporation of ${ }^{14} \mathrm{C}$ into sucrose and an increase in the label incorporation into hexoses (Table 2) in fiber flax, in which during the period of rapid growth the main consuming organs are the growing apex and roots. The presence of a long stem with a large number of functionally equivalent source leaves with short, but clearly visible petioles, allowed us to trace the dynamics of the movement of labeled assimilates in both the ascending and descending directions by introducing ${ }^{14} \mathrm{CO}_{2}$ into the leaves of the middle plant part.

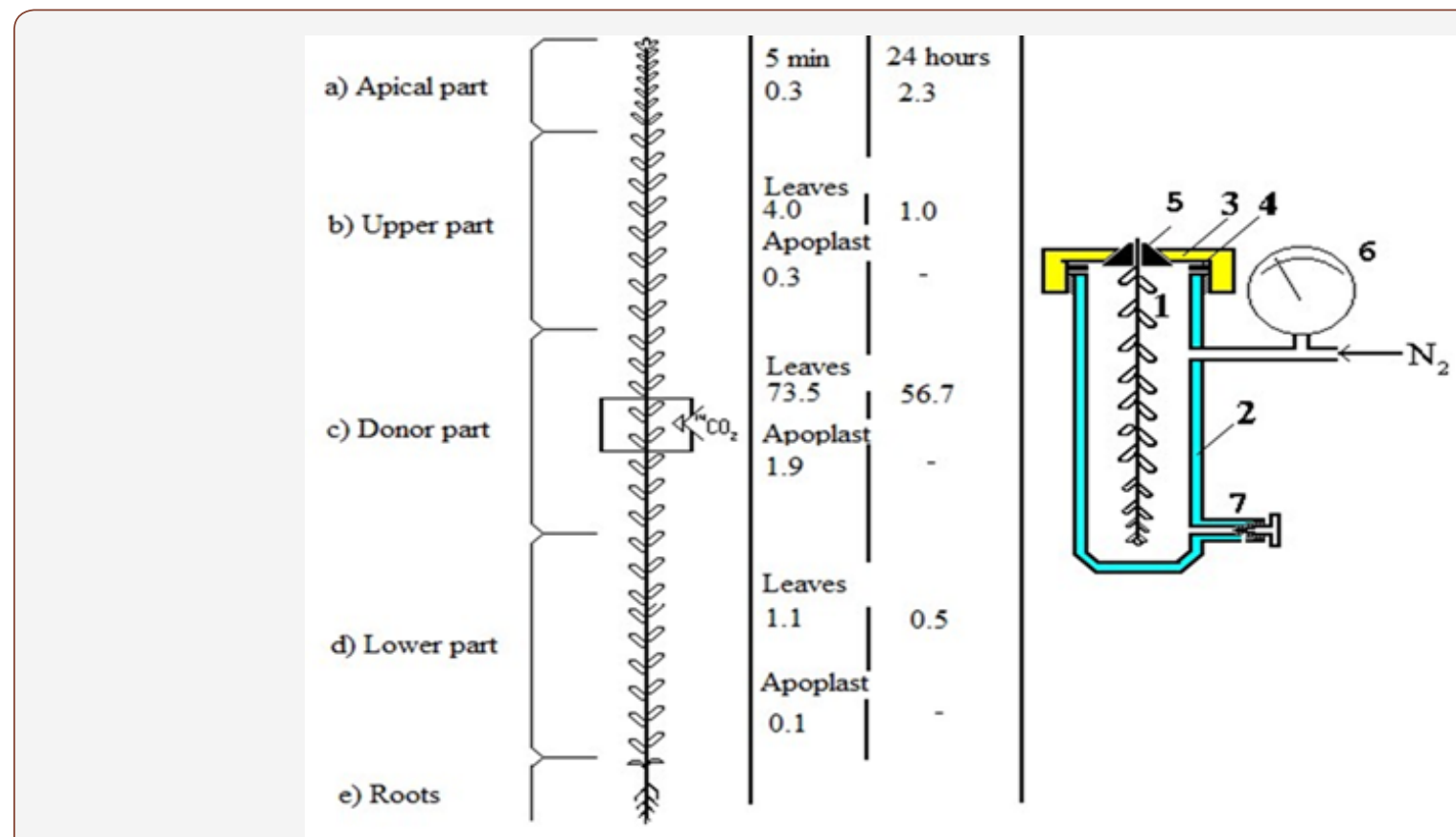

Figure 8: Scheme of using a pressure chamber for extracting labeled assimilates from the apoplast of fiber flax [36]. Symbols as in Figure 1.

The experiment was carried out as follows. Nine to ten leaves in the middle part of the shoot were fed with ${ }^{14} \mathrm{CO}_{2}$ in the light (Figure 8). After 2 minutes of ${ }^{14} \mathrm{CO}_{2}$ assimilation the shoot was cut (in 5 minutes or 24 hours after exposure to ${ }^{14} \mathrm{CO}_{2}$ ) and divided into three parts (as shown in Figure 8), with the site that assimilated ${ }^{14} \mathrm{CO}_{2}$ remaining in the middle section. Each section was immediately infiltrated with water and the labeled assimilates from the apoplast were recovered. Then, using a pressure chamber, extracellular fluid was isolated and ${ }^{14} \mathrm{C}$ content in various compartments (apex, leaves and apoplast above and below the donor site) was evaluated.

Significant differences were found in the contents of labeled carbon above and below the ${ }^{14} \mathrm{C}$ donor site of the shoot [17]. After 5 minutes, the radioactivity of tissues was greater in the upper part of the shoot than in the lower part. This pattern was also observed in the apoplast. ${ }^{14} \mathrm{C}$-carbon was detected in much larger quantities in the leaves than in the stem or apex. ${ }^{14} \mathrm{C}$ was transported at a speed exceeding $10 \mathrm{~m} / \mathrm{hr}$. in the ascending direction and about 40-50 $\mathrm{cm} / \mathrm{hr}$ in the descending direction. The latter corresponded to the rate of movement of photosynthetic products in the phloem [1]. In general, our analysis of ${ }^{14} \mathrm{C}$ content in various parts of the plant confirmed the findings presented in [33].

The rapid transfer of labeled assimilates to the upper part of the shoot (primarily transpiring leaves) indicated their release into the apoplast during their movement along the sieve tubes of the stem. Assimilates released into the leaf apoplast cannot be transported through the apoplast to the stem, since in this case they would have to move in the leaf petiole against the intense flow of transpiration water. Assimilates, formed in the chlorenchyma tissues of the stem cortex, do not make a significant contribution to the ascending flow. There are two reasons for this. Photosynthetic assimilation of $\mathrm{CO}_{2}$ by stem tissues does not exceed $15 \%$ of that of the whole plant, and less than $20 \%$ of them are exported [34]. After going to the apoplast of the stem, assimilates are apparently transported upwards through the apoplast of the wood and the bark tissues with the transpiration water stream, because only water moves through the plant at such a rate. The available data obtained by physical methods (pulsed NMR) indicate that water moves upwards not only along the xylem, but also along the cell walls of other stem tissues [35].

In the first 5 minutes most of the labeled assimilates in the upper part of the shoot entered the leaves that had completed growth due to their higher transpiration. ${ }^{14} \mathrm{C}$ entered in much smaller quantities to the apex, containing juvenile leaves with poorly developed stomata. Since the phloem elements are in the stem bast, and not in the wood, the radioactivity of the latter was lower than those in the bast or leaves in all shoot parts in 5 min [36]. This also confirms the movement of labeled assimilates in the apoplast of bast tissue. Contributed to this also the fact that the stream of water moving in the xylem from the lower shoot part does not contain labeled assimilates, because 5 minutes is too little for their sufficient movement along the phloem to the lower shoot part. 
Analysis of ${ }^{14} \mathrm{C}$ distribution in the plant in 24 hours after ${ }^{14} \mathrm{CO}_{2}$ assimilation showed [36] that most of the labeled carbon exported from the shoot donor part ended in the lower plant part (mainly in wood). The ${ }^{14} \mathrm{C}$ content in the apex increased during this period, and in the upper and lower leaves that had completed growth, it decreased. Reduction of radioactivity in the fully grown leaves of the upper shoot part was observed not only in relative units (\%), but also in units of carbon ( $\mathrm{kBq}$ ). Of the total amount of labeled carbon that entered the upper leaves in the first minutes (74.0 and 180.8 $\mathrm{kBq}$ in unfertilized and nitrogen-fertilized plants, respectively), no more than $20 \%$ remained after 24 hours (12.4 and $26.4 \mathrm{kBq}$, respectively).

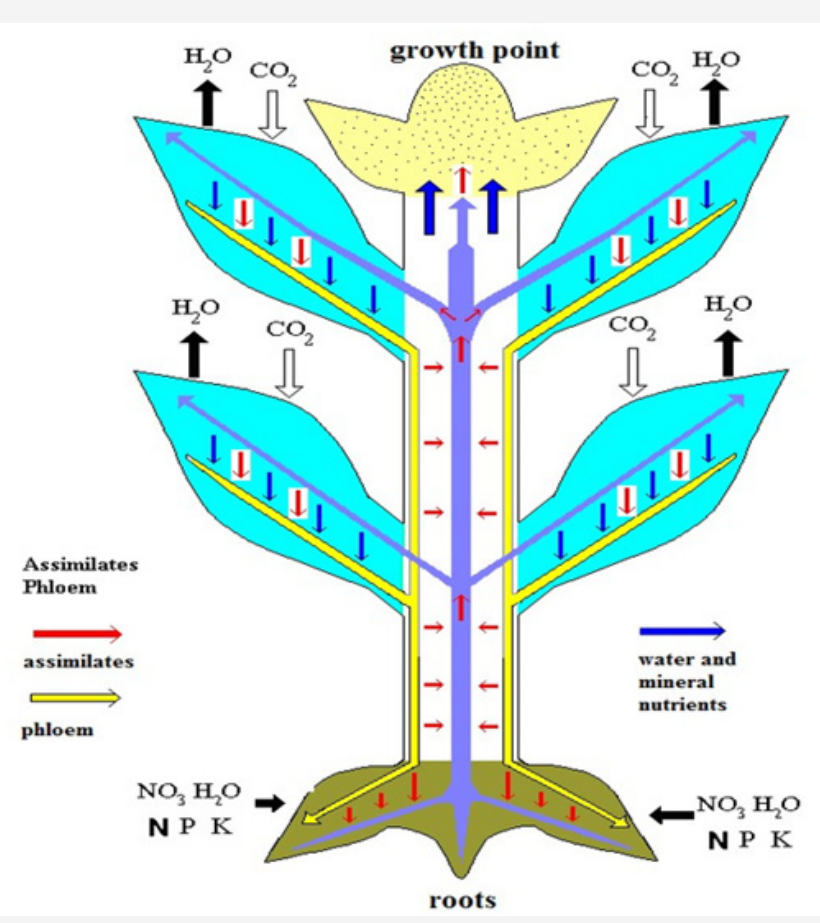

Figure 9: Scheme of assimilate circulation in the plant (downwards in the phloem, upwards in the apoplast with the transpiration water).

These data indicate that labeled assimilates transported to the upper fully grown leaves are absorbed to a very small extent, but mostly re-loaded into the phloem and re-exported in downward direction. In this case, the acceptor leaves play the role of donors of "foreign" assimilates. During their downward transport along the stem sieve tubes, these assimilates can once again go into the apo plastic space and be transported upwards with the water stream. All this allowed to conclude [17,36,37] that assimilates circulate in the plant for a long time, descending along the phloem sieve tubes, and being transported through the common apoplast to the xylem and with the ascending transpiration water stream upwards (as shown in Figure 9). With this mechanism, on the one hand, the concentration of assimilates in the apoplast of different plant parts is leveled, and on the other hand, they can be redistributed to certain organs in accordance with a change in their transpiration level.

The sucrose released into the apoplast may, apparently, partially return back, since the ability of the conducting bundles to intensively absorb sucrose from an external solution has long been shown [38] and there are specific transport proteins mediating sucrose retrieval into phloem [39]. However, considering the high rate of transpiration (whose intensity is 2-3 orders of magnitude higher than that of photosynthesis), a certain part of assimilates released into the apoplast is undoubtedly carried upwards and included in the circulation along the plant.

Thus, the apoplast of a plant can be regarded as a single container of "common" assimilates, from which they can be equally successfully absorbed by any plant organs in accordance with their needs, with the phloem transferring them downwards and the apoplast - upwards. The intensification of metabolic processes or transpiration in any plant part, for example, in an ovary of a fruit or in a shoot exposed to light, will result in increased consumption of assimilates from this apo plastic pool and vice versa.

Apparently, this is the mechanism of the action of the "request" for assimilates from sink organs. With a decrease in the concentration of assimilates in the common pool (including the apoplast of source leaves), photosynthetic activity of the leaf will be increased. Of course, it is likely that certain barriers may occur along the path of assimilate movement in the apoplast, which contribute to the intensity of the supposed circulation; however, the experimental results discussed above evidence the existence of such a phenomenon.

The results of [17] can probably be regarded as relevant only to fiber flax plants. However, fast and slow components of transport of labeled assimilates were also found in plants such as cotton [40], and lupine [33]. The presence of the "severe law" (a minor exchange of assimilates between mature leaves) in many plant species [1] also speaks in favor of the idea of assimilating circulation in the plant involving the apoplasts.

The ascending streams of transpiration water in some plant species apparently have certain limitations of mixing. And in this case the circulation is carried out within the limits defined by the orthoses, symposial branches or a separate leaf. This is, probably, the basis of the existence of different orders of sink-source systems, pointed out by AT Mokronosov [41]. The ground for this conclusion is also the data on the asymmetric intake of labeled assimilates at feeding leaves on one side of the stem [1].

The literature data presented above, and the data of our experiments indicate an important role of the apoplast in the regulation of the plant photosynthetic function and allow us to draw some conclusions.

- In the apo plastic plant type, the assimilates go into the apoplast not only of the leaf (during sucrose loading into phloem terminals) but also of the stem, and can circulate for a long time, moving downward along the phloem tubes, and upward with the transpiration water stream, creating a common pool in the apoplast of the whole plant, used by all organs of the plant.

-When studying the mechanism of the "request" for assimilates by sink organs, it is necessary to take into account the possibility 
of assimilating absorption from the common apo plastic pool. The change in the concentration of assimilates in this pool can trigger a mechanism for the normalization of sink-source relationships, which researchers could not find for 50 years.

- The nature of the "severe law" (a minor exchange of assimilates between mature leaves) is not the prohibition of assimilate influx into these leaves, but the active "loading" of "foreign" assimilates into the phloem in the apoplast of these leaves.

- The nature of the long-known principle according to which the assimilates of the upper leaves get more into the ear, and those from the lower ones to the roots [32] is explained by the fact that assimilates of the upper leaves are more likely to get to the stem apoplast and move to the upper part of the shoot, since the time of their movement along the stem phloem sieve tubes, washed by the counter-flow of the transpiration water, is longer. Conversely, the assimilates from the lower leaves have a shorter way to go to roots and therefore it easier for them to get there.

An interesting approach to the search of a role for apoplast in the regulation of photosynthesis can be a study of photosynthetic apparatus functioning when solutions of various substances (nitrogen forms, regulatory substances, inhibitors, substances changing the apoplast cation composition, etc.) are fed through the transpiration water stream (under the pressure equal to the root pressure).

\section{Features of $14 \mathrm{C}$ distribution among the labeled products of photosynthesis in leaf mesophyll cells and the apoplast}

Table 3: Distribution of ${ }^{14} \mathrm{C}$ among labeled photosynthetic products in the leaves and apoplast of fiber flax plants after 5 minutes assimilation of ${ }^{14} \mathrm{CO}_{2}$ (\% radioactivity of alcohol-water-soluble fraction).

\begin{tabular}{|c|c|c|c|c|}
\hline \multirow{2}{*}{$\begin{array}{c}\text { Labeled } \\
\text { Substances }\end{array}$} & \multicolumn{2}{|c|}{ Upper Shoot Part } & \multicolumn{2}{c|}{ Donor Shoot Part } \\
\cline { 2 - 5 } & Leaves & Apoplast & Leaves & Apoplast \\
\hline Sucrose & $73.5 \pm 0.6$ & $89.7 \pm 0.2$ & $60.9 \pm 0.5$ & $89.6 \pm 0.5$ \\
\hline Hexoses & $4.8 \pm 0.4$ & $0.6 \pm 0.2$ & $3.6 \pm 0.2$ & $0.7 \pm 0.1$ \\
\hline Amino Acids & $10.0 \pm 0.6$ & $4.1 \pm 0.2$ & $15.1 \pm 0.3$ & $3.9 \pm 0.4$ \\
\hline Malate & $3.2 \pm 0.2$ & $2.2 \pm 0.1$ & $4.0 \pm 0.1$ & $2.1 \pm 0.1$ \\
\hline Other Substances & $8.5 \pm 0.2$ & $3.3 \pm 0.8$ & $16.4 \pm 0.7$ & $3.7 \pm 0.1$ \\
\hline $\begin{array}{c}\text { Sucrose to } \\
\text { Hexoses }\end{array}$ & 15 & 149.5 & 16.9 & 128 \\
\hline
\end{tabular}

The distribution of ${ }^{14} \mathrm{C}$ among the labeled products of photosynthesis in mesophyll cells and in the apoplast varies significantly (Table 3). Among photosynthetic products of mesophyll cells, relatively more ${ }^{14} \mathrm{C}$ is contained in amino acids and hexoses, but less in sucrose compared to the apoplast. As a result, the ratio of labeled sucrose to hexose is much higher in the apoplast than in mesophyll cells [36]. The apoplast has high label content in malate (similar to intracellular one). This confirms the earlier conclusion [42] that malate performs the function of a transport compound for potassium ion. And this malate is most likely to be of photosynthetic origin, since the influx of ${ }^{14} \mathrm{C}$-malate from roots with the xylem sap depends on the provision of the latter with assimilates $[43,44]$ and sharply decreases in the case of plant defoliation.

Free labeled hexoses in the leaf can be formed either as a result of dephosphorylation of the corresponding sugar phosphates (and this would most likely occur in the cytosol) or hydrolysis of the newly synthesized ${ }^{14} \mathrm{C}$ sucrose by invertase [32]. It is known that invertase is present in various compartments of the leaf: in the cytoplasm, vacuole and in the apoplast [45]. Higher invertase activity in different leaf compartments leads to a greater use of sucrose within the assimilating cells themselves, which causes the accumulation of starch and hexoses [46]. A key role of apo plastic invertase during senescence was shown [47].

To elucidate the role of various compartments in the metabolism of sucrose, yeast invertase was expressed in the apoplast, vacuole, or cytosol of tobacco plants $[48,49]$. All transgenic plants showed a delay in growth. Accumulation of starch and hexoses in leaves indicated that assimilates were poorly exported. At the invertase expression in the cytosol, this effect was observed in both young and old leaves. In the case of invertase expression in the apoplast or vacuole, the induced phenotypic changes were observed only in the old leaves-exporters of assimilates.

Similar experiments in potato [46] showed the similarity of all lines of transgenic plants to control plants grown under water stress. The transformants were delayed in growth, accumulated hexoses and amino acids, especially proline the level of which was 40 times higher than that in wild type plants. In all transformants, the rates of assimilation and leaf conductance for $\mathrm{CO}_{2}$ were lowered, which indicated a regulatory link between the invertase and the operation of the stomata.

It is known that the ratio of radio activities of photosynthetically labelled sucrose to hexoses is a sensitive indicator of the reaction of photosynthetic carbon metabolism to different impacts. Any influence suppressing photosynthesis or decreasing export of assimilates leads, first of all, to a decrease in the synthesis of sucrose and the ratio of labeled sucrose to hexose. The analysis of changes in photosynthesis and photosynthetic carbon metabolism under various influences [24] showed that the main reason of a change in photosynthetic carbon metabolism is a decrease in the sucrose export from the leaf.

Initially, in the case of drought, this hypothesis was based [24] on the decrease in the metabolic activity of sinks for assimilates due to higher sensitivity of cell division in meristematic tissues to dehydration, as well as on the facts of cellulose accumulation under drought conditions (development of xeromorphism). In view of our recent data, it can be assumed that these signs may be secondary and are a result of a decrease in the export of sucrose. The latter probably occurs because of enhancement of sucrose hydrolysis by acid apo plastic invertase, with the products of the hydrolysis (hexoses) being transferred from the apoplast to the mesophyll cells and causing re-activation of the leaf growth by expansion. In our experiments with removal of assimilate consuming organs in 
cotton plants, the leaves that had completed growth could increase their size by a factor of 1.5-2 during a few days after the treatment. In the case of the influence of enhanced nitrogen nutrition on photosynthesis (also causing inhibition of assimilate export from the leaf), this conclusion can be confirmed by calculating the concentration of labeled hexoses in these two compartments.

C content in mesophyll cells and the apoplast was 1414 and $33.1 \mathrm{kBq}$ in unfertilized and 3322 and $85.9 \mathrm{kBq}$ in fertilized plants, respectively [36]. The volume of the liquid phase of mesophyll cells is $90 \%$ of the volume of the leaf [13], and the part of the extracellular space where H+-ATPases are located [30] participating in the transport of sucrose probably does not exceed $10 \%$ of the total volume of the apoplast (i.e. $1 \%$ of the volume of the leaf

Table 4: ${ }^{14} \mathrm{C}$ contents $(\mathrm{kBq})$ in hexoses in leaf mesophyll cells and apoplast.

\begin{tabular}{|c|c|c|c|c|}
\hline \multirow{2}{*}{ Indices } & \multicolumn{2}{c|}{ Non-Fertilized Plants } & \multicolumn{2}{c|}{ Plants Fertilized with Nitrogen } \\
\cline { 2 - 5 } & Mesophyll Cells & Apoplast & Mesophyll Cells & \multicolumn{1}{c|}{ Apoplast } \\
\hline C contents in donor leaves & 1414 & 33.1 & 3322 & 85.9 \\
\hline${ }^{14} \mathrm{C}$ contents in the fraction of low molecular weight substances & 990 & 33.1 & 2325 & 97.6 \\
\hline${ }^{14} \mathrm{C}$ contents in hexoses & 35.6 & 0.23 & 1.7 \\
\hline The same as calculated per volume unit of the compartment* & 0.39 & 0.23 & 1.08 & 1.72 \\
\hline
\end{tabular}

Apoplastic invertase as a key enzyme in the regulation of the export of sugars from leaf

A key role in understanding of the role of invertase in the regulation of photosynthesis and the transport of assimilates from the leaf was played by experiments in which plants with a genetically suppressed invertase activity were subjected to a simultaneous $\mathrm{CO}_{2}$ and $\mathrm{H}_{2} \mathrm{O}$ gas exchange analysis. Measurements of the leaf and plant steady-state gas exchange, when all metabolic flows are coordinated, showed a slight increase in the rates of $\mathrm{CO}_{2}$ and $\mathrm{H}_{2} \mathrm{O}$ gas exchange rates in the transformed compared to wild type plants. However, when the illumination of plants was reduced by $50 \%$, different changes in photosynthesis and transpiration took place in wild and transformed plants.

In the wild type plants photosynthesis and transpiration simultaneously decreased under reduced illumination, as is usually observed. In transformed plants with suppressed apo plastic invertase activity, photosynthesis slightly decreased (due to a decrease in light energy), but transpiration increased. This indicated that at a decrease in light energy, most of $\mathrm{CO}_{2}$ fixation products (organic acids) were not reduced to sugars and, as a result, the acidity increased, first, inside the chloroplast space, and then in the mesophyll and the apoplast. The decrease in the $\mathrm{pH}$ of the extracellular space activated the apo plastic invertase in control plants, but this did not occur in transformed plants. In the case of invertase activation, the osmolarity of the medium increased (one mole of sucrose $\rightarrow$ two moles of hexoses). As a result of the increase in apoplast osmolarity, the turgor of the stomatal guard cells decreased, and they closed the stomata. This did not happen in the transformed plants. Moreover, non-hydrolyzed sucrose liquid phase). Considering this circumstance, in our experiments ${ }^{14} \mathrm{C}$-hexose content in mesophyll cells and the apoplast was (per unit volume of the compartment) $0.39 \pm 0.04$ and $0.23 \pm 0.02$ in control plants and $1.08 \pm 0.13$ and $1.70 \pm 0.12 \mathrm{kBq}$ in nitrogenfertilized plants, respectively. This means that the concentration of hexoses in the extracellular space of fertilized plants may be* it is conventionally accepted that the volume of mesophyll cells is $90 \%$ of the volume of the entire leaf liquid phase, and the apoplast volume comprises only a part of the extracellular zone between mesophyll cells and companion cells - 1\%.

Higher than in mesophyll cells (Table 4). This also indicates the vector of hexose movement from the apoplast to the mesophyll. continued to be successfully loaded into the phloem. As a result, the concentration of osmotic substances in the apoplast fell and stomatal guard cells could raise their turgor, decreasing stomatal resistance to gas diffusion into a leaf. This slightly increased $\mathrm{CO}_{2}$ diffusion into the leaf reduced (but not eliminated) the suppression of photosynthesis.

Researchers studying photosynthetic gas exchange are well aware that photosynthesis and transpiration always change synchronously. This is confirmed by the analysis of diffusion resistances to $\mathrm{CO}_{2}$ and $\mathrm{H}_{2} \mathrm{O}$ in the system of mesophyll cells stomatal cavities - gas phase around the leaf [48]. However, it is not known how the regulatory relationship between stomatal resistance and photosynthetic carbon metabolism is carried out. Meanwhile, photosynthetic carbon metabolism varies greatly and is sensitive to changes in conditions, resulting in a varying qualitative composition of photosynthetic products.

Thus, there is a regulatory system in the leaf [6], combining photochemical processes in chloroplasts, cell photosynthetic carbon metabolism, apoplastic invertase and stomata, which reacts to changes in light intensity, nitrogen (nitrate) nutrition level, activity of growth processes in sink organs and optimizes the entire photosynthetic function of the plant. The key trigger mechanism in all cases (Figure 10) is probably the use of products of photochemical reactions in chloroplasts (primarily NADP.H). When nitrate concentration increases in the leaf, the competition of nitrite for electrons of the chloroplast's electron transport chain increases. As a result, $\mathrm{CO}_{2}$ assimilation reacts to a decrease in the amount of reducing agent formed and, consequently, all subsequent changes occur as described above. 


\section{Increased amount of photosynthetic products (NADPH and ATP) (for example, illumination has increased)}

\begin{tabular}{|c|c|c|c|c|c|}
\hline $\begin{array}{l}\text { All fixed } \mathrm{CO}_{2} \text { is } \\
\text { reduced to sugars. } \\
\text { Low amount of } \\
\text { organic acids }\end{array}$ & $\begin{array}{l}\text { Sugars are } \\
\text { successfully } \\
\text { exported. } \\
\text { Increased } \\
\text { apoplastic pH }\end{array}$ & $\begin{array}{l}\text { Suppressed } \\
\text { apoplastic inverase } \\
\text { activity. Sucrose is } \\
\text { successfully } \\
\text { exported }\end{array}$ & $\begin{array}{l}\text { Decreased } \\
\text { extracellular } \\
\text { medium osmolarity }\end{array}$ & $\begin{array}{l}\text { Stomata open. } \mathrm{CO}_{2} \\
\text { diffusion into leaf } \\
\text { proceeds } \\
\text { successfully }\end{array}$ & $\begin{array}{l}\text { Photosynthesis } \\
\text { increases and } \\
\text { corresponds to the } \\
\text { amount of } \\
\text { photosynthetic } \\
\text { products }\end{array}$ \\
\hline
\end{tabular}

\section{Photosynthetic products (NADPH and ATP) deficiency (for example, illumination has decreased)}

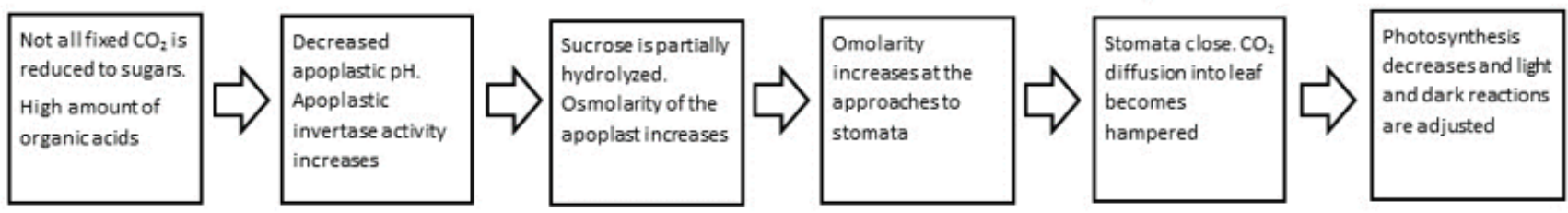

Figure 10: The involvement of the apo plastic invertase in the regulation of photosynthesis under changes in the ratio of $\mathrm{CO}_{2}$ assimilation and the flux of light energy.

Under inhibition of assimilate export from the leaf (for example, as a result of a decrease in the number or activity of sink organs), it will be difficult to load sucrose into an overfull phloem. There will be an increase in its concentration in the apoplast, which will cause vacuolization of the phloem companion cells (as it is observed at an increase in the concentration of nitrates or NO [43,50-62]), activation of the invertase by its substrate, increased sucrose hydrolysis and subsequent stomatal closure.

\section{Conclusion}

The resulting large quantities of hexoses will return to mesophyll cells and interfere with the metabolism of triose phosphates, leaving the chloroplasts, which will lead to activation of the Mehler reaction and appearance of glycolate of the transketolase origin. The carbon of glycolate metabolism products cannot return to the Calvin-Benson cycle and will replenish the pool of acids with subsequent effects on the invertase activity and the stomatal guard cells. In addition, the accumulation of hexoses in the cytoplasm and the non-return of inorganic phosphate to chloroplasts will enhance the synthesis of starch in chloroplasts. All this will increase photorespiration, which will protect the chloroplast photosynthetic apparatus from photo-destruction.

\section{Acknowledgement}

None.

\section{Conflict of Interest}

No conflict of interest.

\section{References}

1. Kursanov AL (1976) Transport of assimilates in the plant. pp. 568.

2. Brovchenko MI (1970) Hydrolysis of sucrose in the free space of leaf tissues and localization of invertase. Sov Plant Physiol 17: 31-39.

3. Chikov VI (1982) Determination of the water potential of plants. In Methods for studying water exchange in plants, Pp. 60-73.

4. Dixon HH (1914) Transpiration and the ascent of sap in plant.

5. Muhling KH, Sattelmacher B (1997) Determination of apoplastic $\mathrm{K}^{+}$in intact leaves by ratio imaging of PBFI fluorescence. Journal of Experimental Botany 48: 1609-1614.
6. Chikov V, BakirovaG, Avvakumova N (1998) Transpiration has a function of assimilate redistribution in the whole plant. -In Garab G (ed.), Photosynthesis: Mechanisms and Effects. Proceedings of the $\mathrm{XI}^{\text {th }}$ International Congress on Photosynthesis 5: 3739-3742.

7. Gusev NA (1974) The state of water in plants.

8. Belkovich TM, Gusev NA About the factors influencing water-retaining ability of cells.

9. Chikov VI, Ivanova NP, Isfandiyarov NI (1983) Study of water exchange of plant leaves with the help of a pressure chamber and membraneactive substances. Physiol Biochemistry Cultivated Plants 15: 466-470.

10. Chikov VI, Yargunov VG, Muraveva (1978) AS On the measurement of water potentials using a pressure chamber. In Water Regime of Plants in Relation to Different Ecological Conditions.

11. Rakhi M (1973) Apparatus for studying the components of the water potential of leaves. Sov. Plant Physiol. 20: 215-221.

12. Bernstein L (1971) Method for determining solutes in the cell walls of leaves. Plant Physiol 47(3): 361-365.

13. Brovchenko MI (1981) Apparatus for the extraction of soluble substances from the apoplast of an intact leaf. Sov Plant Physiol 28: 1091-1095.

14. Lohaus G, Winter H, Riens B, Heldt HW (1995) Further studies of the phloen loading process in leaves of barley and spinach. The comparison of metabolite concentrations in the apoplastic compartment with those in the cytosolic compartment and in the sieve tubes. Bot Acta 108(3): 270275 .

15. Lu P, Zhang SQ Outlaw WH, Riddle KA (1995) Sucrose: a solute that accumulates in the guardcell apoplast and guard-cell symplast of open stomata. FEBS Lett 362: 180-184.

16. Lu P, Outlaw WH, Smith BG, GA Freed (1997) A new mechanism for the regulation of stomatal aperture size in intact Leaves (Accumulation of mesophyll-derived sucrose in the guard-cell wall of Vicia faba). Plant Physiol 114: 109-118.

17. Ruan YL, Patrick JW, Brady CJ (1996) The composition of apoplast fluid recovered from intact developing tomato fruit. Aust J Plant Physiol 23(1): 9-13.

18. Muhling KH, Plieth C, Hansen UP, Sattelmacher B (1995) Apoplastic pH of intact leaves of Vicia faba as influenced by light. Journal of Experimental Botany 46(4): 377-382.

19. Canny MJ (1995) Apoplastic water and solute movement. New rules for an old space Annu Rev.

20. Husted S, Schjoerring JK (1995) Apoplastic $\mathrm{pH}$ and $\mathrm{NH}^{4+}$ concentration in leaves of Brassica napus L. Plant Physiol 109(4): 1453-1460.

21. Tarchevsky IA (1964) Photosynthesis and drought. pp. 148. 
22. Savchenko G, Wiese C, Neimanis S, Hedrich R, Heber U (2000) pH regulation in apoplastic and cytoplasmic cell compartments. Planta 211(2): 246-255.

23. Felle HH, Hanstein S (2002) The apoplastic pH of the substomatal cavity of Vicia faba and its regulation responding to different stress factor. J Exp Bot 53(366): 73-82.

24. Chikov VI (1987) Photosynthesis and transport of assimilates. Nauka, Moscow, Pp. 104.

25. Schmitz K (1987) Pathway of assimilate transfer between mesophyll cells and minor veins in leaves of Cucumis melo L. Planta 171(1): 19-29.

26. Kosegarten H, Englisch G (1994) Effect of various nitrogen forms on the $\mathrm{pH}$ in leaf apoplast and on iron chlorosis of Glycine max L.Z Pflanzener Bod 157(6): 401-405.

27. Hoffman B, Kosegarten H (1995) FITC-dextran for measuring apoplast $\mathrm{pH}$ and apoplastic $\mathrm{pH}$ gradients between various cell types in sunflower leaves. Physiol Plant 95(3): 327-335.

28. Oja V, Savchenko G, Jakob B, Heber U (1999) pH and buffer capacities of apoplastic and cytoplasmic cell compartments in leaves. Planta 209(2): 239-249.

29. Heber U, Wiese C, Neimanis S, Savchenko G, Bukhov NG, et al. (2002) Energydependent solute transport from the apoplast into the symplast of leaves during transpiration. Russian Journal of Plant Physiology 49(1): 32-43.

30. Bouche Pillon S, Fleurat Lessard P, Fromont JC, Serrano R, Bonnemain JL (1991) Immunolocalization of the plasma membrane $\mathrm{H}^{+}$-ATPase in minor veins of Vicia faba in relation to phloem loading. Plant Physiol 105(2): 691-697.

31. Geilfus CM (2017) The pH of the apoplast: dynamic factor with functional impact under stress. Mol Plant 10(11): 1371-1386.

32. Kursanov AL (1984) Endogenous regulation of transport of assimilates and sink-source relations in plants. Sov Plant Physiol 31: 579-595.

33. Minchin PEH, Mc Naughton GS (1987) Xylem transport of recently fixed carbon within lupin. Aust J Plant Physiol 14(3): 325-329.

34. Chikov VI, Bakirova GG, Ivanova NP, Nesterova TN (1997) The assimilation of labeled carbon by individual parts of fiber flax and its distribution. Physiol Biochem Cultivated Plants 29: 93-99.

35. Anisimov AV, Ratkovich S (1992) Transport of water in plants. Investigation by the pulsed NMR method.

36. Chikov V, Avvakumova N, Bakirova G, Maklashova L (2001) Apoplastic transport of 14Cphotosynthates measured under drought and nitrogen supply Biol Plant 44: 517-521.

37. Chikov V, Bakirova G (1999) Relationship between carbon and nitrogen metabolism in photosynthesis. The role of photooxidation processes. Photosynthetica 37: 519-527.

38. Sonnewald U, Brauer M, von Schaewen A, Stitt M, Willmitzer L (1991) Transgenic tobacco plants expressing yeast-derived invertase in either the cytosol, vacuole or apoplast: a powerful tool for studing sucrose metabolism and sink/source interactions. Plant J 1(1): 95-106.

39. Ayre BG (2001) Membrane-transport systems for sucrose in relation to whole-plant carbon partitioning. Mol Plant 4(3): 377-394.

40. Pinkhasov, YuI (1978) Study of the nature of the ultrafast transport of assimilates in phloem. -In Anisimov, AA, Opritov VA Biochemical and biophysical mechanisms of substance transport in plants and its regulation. pp. 121-122.
41. Mokronosov AT (1983) Photosynthetic function and integrity of the plant organism. XLII Timiryazev readings.

42. Lips SG (1997) Role of inorganic nitrogen ions in plant adaptation processes. Russ Plant Physiol 44(4): 421-431.

43. Bakirova, Chikov (1993) Plant Physiologists. St. Petersburg 3: 255.

44. Chikov VI, Bakirova GG, Batasheva SN, Sergeeva (2005) AA Effect of defoliation or excision of growing axillary shoots on the composition of labeled products of photosynthesis in the leaves and xylem sap of kidney bean. Russ J Plant Physiol 52: 459-462.

45. Sturm A (1999) Invertases. Primary structures, functions, and roles in plant development and sucrose partitioning. Plant Physiol 121(1): 1-8.

46. Bussis D, Heineke D, Sonnewald U, Willmitzer L, Raschke K, et al. (1997) Solute accumulation and decreased photosynthesis in leaves of potato plants expressing yeast'derived invertase either in the apoplast, vacuole or cytosol. Planta 202(1): 126-136.

47. Martinez DE, Guiamet JJ (2014) Senescence-related changes in the leaf apoplast. Journal of Plant Growth Regulation 33(1): 44-55.

48. Laysk AKh (1977) Kinetics of photosynthesis and photorespiration in C3 plants.

49. Batasheva SN, Abdrakhimov FA, Bakirova GG, Chikov VI (2007) Effect of nitrates supplied with the transpiration flow on assimilate translocation. Russian Journal of Plant Physiology 54(3): 373-380.

50. Batasheva SN, Abdrakhimov FA, Bakirova GG, Isaeva EV, Chikov VI (2010) Effects of sodium nitroprusside, the nitric oxide donor, on photosynthesis and ultrastructure of common flax leaf blades. Russian Journal of Plant Physiology 57(3): 376-381

51. Bakirova GG, Chikov VI Influence of defoliation and removal of organs consuming assimilates on the composition of the xylem sap.

52. Gusev NA, Water exchange and physiological processes of plants. Pp. 9-13.

53. (1981) Kazan Publishing.

54. (1995) Plant Physiol. Plant Mol Biol 46: 215-236.

55. Chikov VI (2008) Evolution of notions about relationships between photosynthesis and plant productivity. Russian Journal of Plant Physiology 55(1): 130-143.

56. Chikov VI Role of sink-source relations in the regulation of the plant productivity.

57. Ron Zhina ES (2009) Photosynthesis, Physiology, Ontogeny, Ecology. pp. 206-234.

58. Chikov VI, Ivanova NP Method for determining the physiological activity of a substance.

59. (1992) Certificate of authorship No. 1778697 dated August 1.

60. Chikov VI, Yargunov VG, Fedoseeva EZ, Chemikosova S (1982) Influence of the ratio between the production and consumption of assimilates on the functioning of the photosynthetic apparatus of plants. Sov Plant Physiol 29: 1141-1146.

61. (1978) Kazan University Publishing, Kazan. Pp. 369-373.

62. Sokolova SV, Pristupa NA, Turkina MV (1975) Kinetics of sucrose inflow and localization of sucrose uptake in the tissues of conducting bundle in sugar beet. In Movement of substances in plants in relation to metabolism and biophysical processes 6: 22-29. 